\title{
Reformas del sector Salud en México
}

\section{Health sector reforms in Mexico}

\section{Diana V. Sánchez-Martínez ${ }^{a}$, Jesús C. Ruvalcaba-Ledezma ${ }^{b}$}

\begin{abstract}
:
The reforms in the health sector in Mexico date back seventy-eight years, which have the purpose of making changes in the instances and functions, with the intention of increasing the equity of medical services and thereby achieving universal coverage. These modifications have tried to reduce the structural fragmentation between social security and public health assistance institutes, recognize the right to health protection and include the private sector as a constitutive part of the health sector. However, these reforms still present problems of fragmentation, inefficiency and inequity in the Mexican health system.
\end{abstract}

\section{Keywords:}

Health reform, Health system, medical services, universal coverage.

\section{Resumen:}

Las reformas en el sector salud en México datan de hace setenta y ocho años, las cuales tienen la finalidad de realizar cambios en las instancias y funciones, con la intención de incrementar la equidad de los servicios médicos y con ello lograr una cobertura universal. Dichas modificaciones han intentado disminuir la fragmentación estructural entre institutos de seguridad social y asistencia pública en salud, reconocer el derecho a la protección en salud e incluir al sector privado como parte constitutiva del sector salud. Sin embargo, estas reformas aún presentan problemas de fragmentación, ineficiencia e inequidad en el sistema de Salud Mexicano.

\section{Palabras Clave:}

Reforma de salud, Sistema de salud, servicios médicos, cobertura universal.

\section{Síntesis}

Los objetivos de las reformas en el sector salud en México son disminuir la fragmentación estructural entre los institutos de seguridad social y asistencia pública en salud (Landa \& Palma 2020), reconocer el derecho a la protección en salud e incluir el sector privado como parte constitutiva del sector salud y descentralizar el manejo de los recursos y los programas de salud e introducción de mecanismos de mercado (Fuentes, 2021).

Las estrategias a través de las cuales se llevan a cabo son la instauración de copagos, establecimiento de incentivos para el desarrollo de seguros de salud y la separación de funciones y descentralización de servicios.
Las reformas han pasado por tres generaciones importantes a lo largo del tiempo.

La primera generación ocucrrió en 1943, con la creación del Instituto Mexicano del Seguro Social (IMSS) y de la Secretaría de Salubridad y Asistencia (SSA) a partir de la fusión de la Secretaría de Asistencia y Departamento de Salubridad a fin de cumplir con el artículo 123 constitucional y el derecho a la protección de la salud. También se incluyó el inicio de Instituto Nacional de Salud mediante la creación del Hospital Infantil de México, el Instituto Nacional de Cardiología y el Instituto Nacional de Nutrición, dando paso a la institucionalización médica.

La segunda generación ocurrió entre 1983 y 1988, también conocida como cambio estructural en salud. Comprendió una reforma administrativa y sustantiva que

\footnotetext{
Autor de Correspondencia, Universidad Autónoma del Estado de Hidalgo, https://orcid.org/0000-0002-7660-7234, Email: diana_sanchez8479@uaeh.edu.mx 
involucró a la población no derecho habiente a partir de diez estrategias que incluían aspectos como la modernización de servicios, investigación y desarrollo de recursos. Así como lo la renovación legislativa en la constitución de 1983, la cual comprendió el derecho a la salud, promulgación de la Ley General en Salud en 1984, las Leyes Estatales de Salud y de trescientas normas técnicas.

Finalmente la tercera generación de reformas ocurrió en 1995, que incluyó la descentralización de los serivicios de la SSA de los estados , formulación de paquete básico con 13 intervenciones destinados a la población rural, la certificación de hospitales y de las escuelas de medicina, el diselo de un nuevo modelo institucional (MIAIS), Ley del Seguro Social, implantación del IMSS-AFORE, regulación de instituciones de seguros y formación de instituciones de seguros (Reyes et al, 2019).

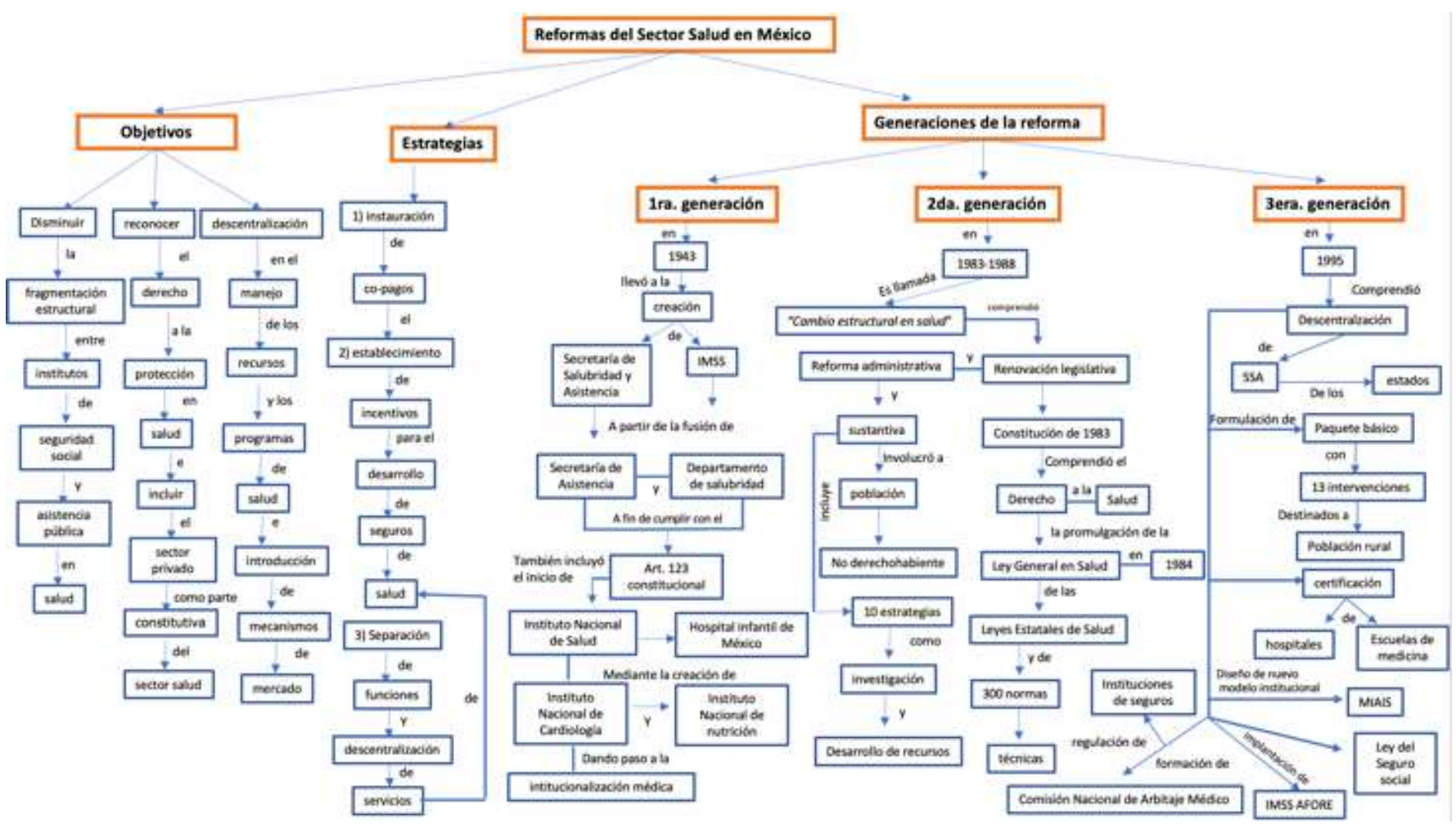

Figura 1. Mapa conceptual de la Reforma del Sector Salud en México.

\section{Referencias}

[1] Fuentes M. (2021). Un desbordado sistema de salud. Recuperado el 29 de septiembre de 2021, de: https://www.mexicosocial.org/un-desbordadosistema-de-salud/

[2] Landa Thierry A. \& Palma L. (2020). La reforma a la Constitución establece el derecho a la salud y los programas sociales en México. Recuperado el 29 de septiembre de 2021, de: https://www.hklaw.com/en/insights/publications/2020/05/la-reforma-a-laconstitucion-establece-el-derecho-a-la-salud
[3] Reyes-Morales, Hortensia, Dreser-Mansilla, Anahí, Arredondo-López, Armando, Bautista-Arredondo, Sergio, \& Ávila-Burgos, Leticia. (2019). Análisis y reflexiones sobre la iniciativa de reforma a la Ley General de Salud de México 2019. Salud Pública de México, 61(5), 685-691. Epub 07 de agosto de 2020.https://doi.org/10.21149/10894 